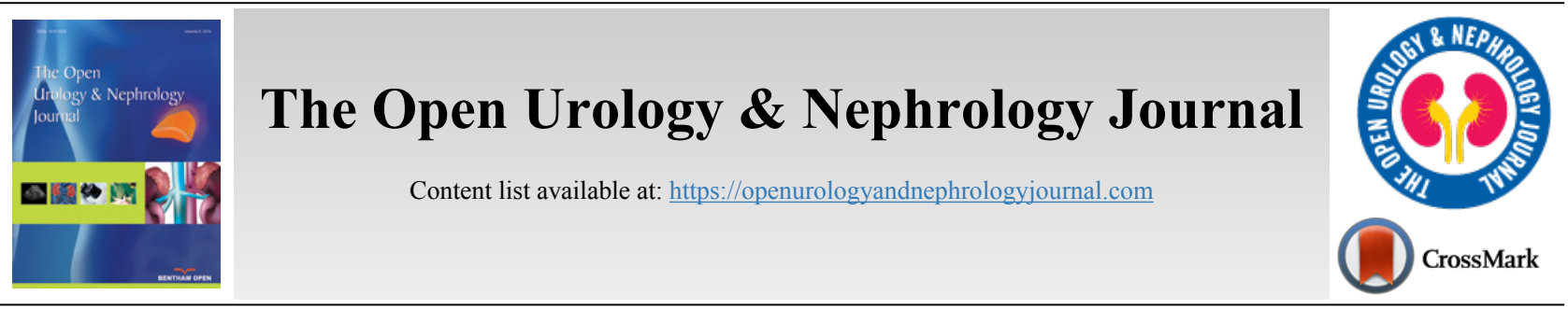

EDITORIAL

\title{
Everyday Cases in Nephrology
}

It gives us a great pleasure to bring to you this special thematic issue for The Open Journal of Urology and Nephrology - Everyday Cases in Nephrology.

Everyday Cases in Nephrology actually started off as a tweet chat session on Twitter in the month of January 2017. The hashtag \#ECNeph was used to popularize the chat session on Twitter. Interesting cases in Nephrology were presented on Twitter and drew an audience from around the world to the discussion. In fact, we analyzed the data on 22 Twitter cases conferences conducted in the 8-month from May to December 2017. A total of 3,957 tweets were recorded during these case conferences [1]. Specialists from 18 countries (including India, Canada, Mexico, China, UK, Myanmar, Malaysia, Spain, Turkey, Serbia, USA, Australia, and the Gulf countries) took part. On an average, 22 doctors joined the \#ECNeph case discussion session with a total of 96 physicians interacting in the sessions during the 8-month period. The number of tweets per learning session varied from 110-316, with a mean of 180 tweets per session (Figure 1).

The total percentage of tweets that included additional media in the form of slides of laboratory findings, radiological investigations, or renal biopsies was $10.45 \%$ (423 tweets). Following a mid-course change in the timings of the \#ECNeph Twitter session from $8 \mathrm{pm}$ Indian Standard Time to $10 \mathrm{pm}$, the number of participants increased from 16 to 22 on average. In a bid to increase our reach, another course change consisted of live streaming of case discussions and the inclusion of guest nephrologists and pathologists in the sessions. Twitter links were provided and enabled 1,242 doctors to view case discussions live through periscope videos of five case discussions on 2 different days.

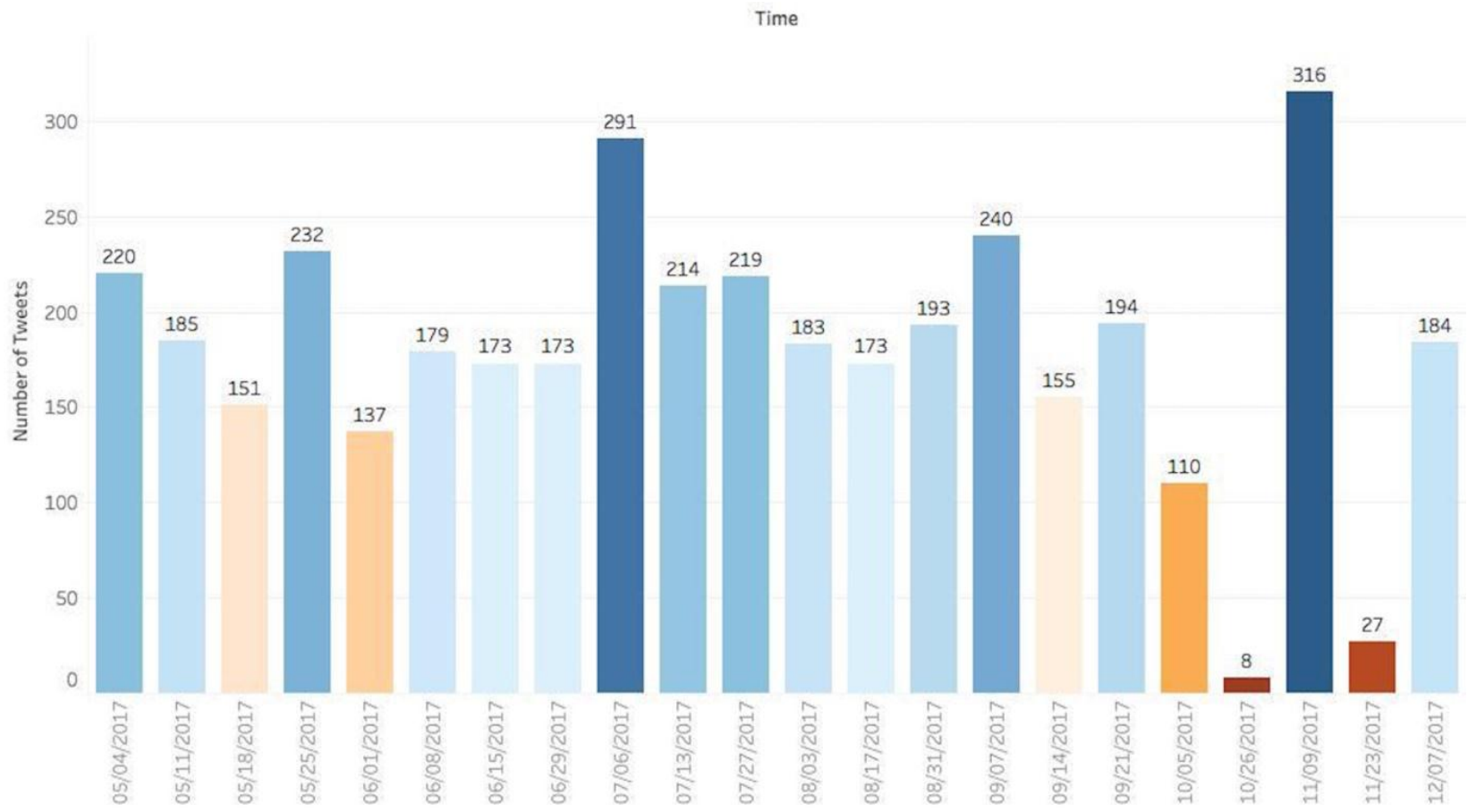

Fig. (1). Bar graph depicting number of tweets during each \#ECNeph session. (Pic courtesy: NOD Analytics). 


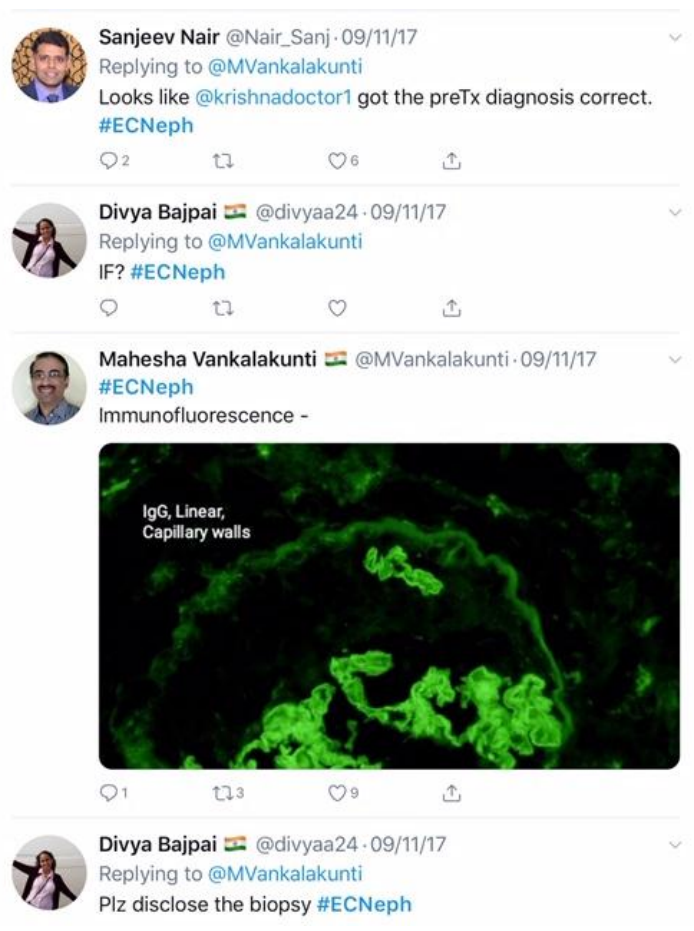

Fig. (2). Picture grab of an \#ECNeph Twitter discussion

Here is an example of one such case that generated a heated discussion on Twitter, a case of Alport Disease with post-transplant graft dysfunction, and that case has been included in this series Fig. (2).

In this series of Everyday Cases in Nephrology, we take a look at some of the interesting cases that we, as Nephrologists get to see during our routine work in this main tropical region, the Indian Subcontinent. The cases vary from the rare Prallethrin poisoning in a child to the not so uncommon urosepsis presenting as limb pain in a dialysis patient. There are learning points with each case and this has been brought out well in the discussion. Each case opens a trail of thought that is unique, but once embedded in the mind, helps it to hopefully "see" more clearly, the next similar case that comes along.

The cases that will be discussed are as follows:

[1] A case of multiple hornet stings causing multi-organ dysfunction syndrome. (Nabin Basnet et al).

[2] Double whammy - Pigment nephropathy and warfarin related nephropathy as aetiology for acute kidney injury in a patient with mechanical heart valves. (Arvind Conjeevaram et al.)

[3] A rare case of co-occurrence of emphysematous cystitis and emphysematous myositis in a haemodialysis patient. (Anupama YJ et al.)

[4] Primary Extranodal Diffuse Large B Cell Lymphoma masquerading as Acute Pyogenic Myositis. A case report. (Manisha Dassi et al.)

[5] A case of anti-Glomerular basement membrane crescentic glomerulonephritis in a female renal allograft recipient with unknown native disease: retrospective molecular confirmation of Alport disease (Mahesha Vankalakunti et al.)

[6] Acute Kidney Injury as a rare complication of Prallethrin (All-Out mosquito repellant liquid) poisoning in a child (Raghunath $\mathrm{CN}$ et al.)

We trust that you folks will enjoy going through these cases as much as we enjoyed putting them together, and more importantly take away some information from each case that will help you in your day to day practice in Medicine and Nephrology.

\section{REFERENCE}

[1] Arvind C, Mahesha V, Garima A, et al. Twitter-Based Case Conferences: An Online Learning Tool for Nephrologists. EMJ Nephrol 2018; 6(1): 47-8. Abstract Review No. AR4.

\section{Guest Editors}

Arvind Conjeevaram

Consultant Nephrologist, The Bangalore and Sagar Hospitals, Bangalore, India

E-mail: canchi8@gmail.com

Anupama Janardhana

Consultant Nephrologist, Nanjappa Hospital, Shimoga, India

E-mail: anupamayj@gmail.com

C) 2019 Conjeevaram and Anupama.

This is an open access article distributed under the terms of the Creative Commons Attribution 4.0 International Public License (CC-BY 4.0), a copy of which is available at: (https://creativecommons.org/licenses/by/4.0/legalcode). This license permits unrestricted use, distribution, and reproduction in any medium, provided the original author and source are credited. 